\title{
Jogos eróticos de sedução? Simmel, Freud e um ensaio sobre coquetismo e histeria
}

\author{
Clark Mangabeira ${ }^{1}$
} Universidade Federal de Mato Grosso

Resumo: Trata-se de um ensaio teórico que pretende aproximar as contribuições das Ciências Sociais e da Psicanálise sobre o jogo erótico da sedução, a partir de escritos demarcados temporalmente (final do século XIX e começo do século XX) de dois autores, Simmel e Freud, conjugando-se, assim, a teoria psicanalítica sobre a histeria e a análise social sobre o coquetismo. O cerne do ensaio é discutir analiticamente as categorias supracitadas na medida em que ambas são hodiernamente acionadas a partir das perspectivas dos autores que as nomearam, seja em termos de crítica ou de aplicação teórica. Assim, busca-se, por fim, demarcar comparações que contribuam ao debate teórico interdisciplinar.

Palavras-chave: Freud; Simmel; histeria; coquetismo.

${ }^{1}$ Professor Adjunto do Departamento de Antropologia da Universidade Federal de Mato Grosso e do Programa de Pósgraduação em Antropologia Social da UFMT. Escritor. Doutor em Antropologia Social pelo Museu Nacional da Universidade Federal do Rio de Janeiro (2014). 


\title{
Erotic games of seduction? Simmel and Freud: an essay on coquetry and hysteria
}

\begin{abstract}
This work is a theoretical essay that aims to bring together the contributions of Social Sciences and Psychoanalysis on the erotic game of seduction. It is based on time-bound writings (late 19th and early 2oth centuries) by two authors, Simmel and Freud, thus combining the psychoanalytic theory about hysteria and the social analysis about coquetry. The core of the essay is to analytically discuss the categories mentioned above, as both are modernly triggered from the perspectives of the authors who named them, whether in terms of criticism or theoretical application. Thus, we seek, finally, to draw comparisons that could contribute to the interdisciplinary theoretical debate.
\end{abstract}

Key words: Freud; Simmel; hysteria; coquetry.

\section{¿Juegos eróticos de seducción? Simmel, Freud y un ensayo sobre coquetería e histeria}

\begin{abstract}
Resumen: Es un ensayo teórico, a fin de reunir las contribuciones de las ciencias sociales y el psicoanálisis sobre el juego erótico de la seducción, basado en escritos de duración limitada (finales del siglo XIX y a principios del siglo XX) de dos autores, Simmel y Freud, abordando así la teoría psicoanalítica sobre la histeria y el análisis social sobre la coquetería. El núcleo del ensayo es discutir analíticamente las categorías mencionadas anteriormente, ya que ambas se desencadenan hoy desde la perspectiva de los autores que las nombraron, ya sea en términos de crítica o aplicación teórica. Así, buscamos, finalmente, establecer comparaciones que contribuyan al debate teórico interdisciplinario.
\end{abstract}

Palabras clave: Freud; Simmel; histeria; coquetería. 
$\mathrm{D}$ efinir pontos nodais de comparação entre dois autores - ou entre suas concepções teóricas - é tarefa árdua. Do ponto de vista ensaístico, o objetivo deste texto é precipitar uma aproximação entre correntes de pensamento que, antes de se excluírem, influenciaram e se influenciam mutuamente, seja pelo polo da complementariedade, seja pelo lado das críticas, réplicas e tréplicas.

Possuindo como plano de fundo a construção binária que, de certa forma, acompanha o desenvolvimento da teoria social desde a fundação das disciplinas, pode-se vincular os fenômenos da histeria e do coquetismo a partir de relações teórico-simbólicas já dadas entre as noções de formas sociais e personalidade ou subjetividade, ou, dito diretamente, entre indivíduo e cultura. Na esteira teórica clássica, é nessa polaridade estruturante do pensamento das Ciências Sociais que se pode - tentar - alocar uma aproximação dos temas freudianos e simmelianos sem cair em uma tentativa de resolução de um pelo outro, de explicação ou sobreposição de um tema pelo outro.

Todavia, convém, antes da comparação teórica, delimitar a leitura com fronteiras críticas. Destarte, fundamental ressaltar que os desdobramentos da teoria psicanalítica sobre a histeria e da análise social sobre o coquetismo foram necessários, indispensáveis e politicamente revistos pelo Movimento Feminista. A discussão sobre a patologização do corpo da mulher pelo olhar do homem ao longo do século XX é fundamental para compreensão mais profunda e redirecionamento dos processos teóricos psicanalíticos e sociais, em especial a partir de revisões fundamentais levadas a cabo por diversas pesquisadoras e autoras. Nessa esteira,

\footnotetext{
Falar (como) mulher (parler-femme) e escrever (como) mulher. A escrita necessariamente provoca outra economia do sentido. Alterando a forma de escrita ou o discurso lógico, aposta Irigaray, outros significados seriam conferidos às mulheres. "[...] o feminino é sempre afetado por e para o masculino. O que queremos pôr em jogo é uma sintaxe pela qual as mulheres possam se autoafetar" (IRIGARAY, 1977/1985: 132). Autoafetar e tocar-se são correlatos a modos de significação em conformidade com o não fechamento feminino, que, em seus termos, consagram-se a desmontar a sintaxe da língua e avistar outra gramática da cultura. (COSSI, 2019: 336)
}

Desta maneira, indica-se, desde já, que o presente ensaio tem como limite substancial a comparação teórica entre a histeria e o coquetismo balizada unicamente a partir das propostas iniciais dos seus autores, ressaltando-se a necessidade de adequação temporal e revisional das mesmas, a partir de críticas já previstas em extensa revisão política e bibliográfica feminista sobre a domesticação do corpo da mulher a partir das projeções masculinas, como, a título não exaustivo de exemplo, vale citar o debate entre Luce Irigaray e Lacan (COSSI, 2019). Consequentemente, o presente trabalho ampara-se apenas na discussão inicial sobre das propostas teóricas sobre o coquetismo e a histeria, com intuito de aproximar discursos do começo do século XX e aprofundar noções que, atualizadas, fomentam discussões até os dias atuais.

Assim, em 1909, Georg Simmel escreveu a "Psicologia do Coquetismo", descrevendo tal fenômeno como um comportamento tipicamente da mulher dentro de um jogo erótico de sedução que, embora leve o comportamento masculino em consideração, possui como centro vital determinadas qualidades lúdicas que são acionadas pelo e no comportamento da mulher. 
Paralelamente, no final do século XIX e começo do XX, Freud, Breuer e outros dedicavam-se ao estudo da histeria e, embora Simmel não comente contribuições da teoria psicanalítica no seu trabalho sobre o coquetismo, parece plausível uma aproximação das duas proposições, o coquetismo e a histeria, dentro de um panorama mais amplo de compreensão e interpretação.

Apesar das óbvias diferenças de método, objetivo, fundamentação teórica e intenção acadêmica, histeria e coquetismo, ao menos nos termos da formulação escrita pelos seus autores enquanto categorias iniciais, foram feitas no mesmo período temporal. Mais, não será espaço aqui destacar as inconsistências e/ou limites dos dois fenômenos analisados (a exemplo do rastreio já citado da bem vinda e necessária crítica feminista tanto à Psicanálise, quanto à Teoria Social), porém tentar, a partir das propostas clássicas delimitadas e temporalmente demarcadas dos autores escolhidos, tecer uma interpretação de mão dupla - a histeria passível de se inferir no comportamento coquete e o coquetismo apresentando uma possível construção social do psiquismo histérico, um intercâmbio conceitual de exercício acadêmico que resvala na ideia de um comportamento coquete-histérico, todavia sem relação causal entre ambos.

Desta maneira, para o sociólogo, enquanto a unidade de análise é a relação dual mulher-homem como forma lúdica de sociação (SIMMEL, 2006) - e, ressalta-se, trata-se de uma análise que ainda não levava em consideração discussões sobre gênero e sexualidade stricto sensu -, Freud foca seu entendimento nas características estruturais do psiquismo, destacando a histeria enquanto um fenômeno que decorre de incompatibilidades na vida representativa, derivativo de um esforço defensivo de esquecimento intencional (FREUD, 1894), no qual "o eu transforma a representação poderosa numa representação fraca retirando-lhe o afeto - a soma de excitação - do qual está carregada" (FREUD, 1894: 56). Consequentemente, para que este exercício teórico tenha validade, fundamental que a comparação já comece sem perder do horizonte essa diferença de nível. Freud e Simmel podem até escrever sobre fenômenos que se revestem de uma capa de comparabilidade possível, mas o fazem a partir de perspectivas diferentes, inclusive metodologicamente.

Isso não impede a comparação necessariamente. Há diferenças de nível de análise, mas também existem pontos de contato que um refinamento teórico mais detido pode revelar no limite do(s) fenômeno(s) enquanto (f)ato(s). Nesse contexto, embora os autores lidem com ordens de realidade distintas - interação, de um lado, e aparelho psíquico e inconsciente, de outro -, nada impede que a análise simmeliana sobre o coquetismo seja afim da interpretação freudiana da histeria, nem, paralelamente, que a análise freudiana da histeria possa ser enredada pela consideração social da relação coquete. Em outras palavras, trata-se, aqui, de enfatizar uma interpretação psicanalítica do fenômeno do coquetismo e, ao mesmo tempo, tecer considerações sociais sobre a histeria, sem reduzir o coquetismo a um sintoma da histeria, nem a histeria a uma construção resolvível pelo parâmetro sociocultural.

Pensando comparativamente, portanto, é basilar para essa aproximação que, apesar de a histeria como discurso ser uma estrutura psíquica, o coquetismo apresenta-se, tal qual Simmel (1909) o descreve, como um comportamento das mulheres, o que se aproxima das considerações iniciais da análise da histeria também centradas a priori nos casos clínicos com mulheres. Assim, escrutinando-se as duas construções teóricas do final do século XIX e começo do XX, e a singula- 
ridade das contribuições datadas, porém até hoje discutidas e aplicadas, o objetivo é aproximar coquetismo e histeria dentro desse mesmo universo feminino, tal qual os autores o conceberam.

Finalmente, este ensaio pretende, novamente, como intuito máximo, aproximar Freud e Simmel na definição de um panorama de compreensão que, primeiro, já possui similaridades em função da proximidade temporal das propostas e, segundo, que pode evocar ressonâncias psicanalíticas do comportamento coquete para sua interpretação e vice-versa, visto que o coquetismo e a histeria não desapareceram enquanto (f)atos sociais e analíticos, considerando-se, obviamente, as refinações teóricas hodiernas.

Simmel (1909) define o coquetismo a partir da construção do amor platônico como "um estado intermediário entre o ter e o não-ter" (Simmel, 1909: 93), alocado na condição de que o amor pode morrer se for alcançado, realizado. $\mathrm{O}$ teramor converter-se-ia, no momento da sua realização, em gozo, em saciedade, desaparecendo em si mesmo. Consequentemente, a condição sine qua non do coquetismo é essa esfera de realização irrealizável de ter o objeto instruído do conteúdo im-pulsional do desejo que, para Simmel (1909), é a esfera fenomenal do amor. Consequentemente, a implicação da coquete tenciona-se sempre entre ter e não-ter, dizer sim e dizer não, provocar e retrair-se.

O comportamento coquete, que Simmel aloca como característica das mulheres - ao menos no contexto do final do século XIX e começo do XX - funda-se no talvez, na dúvida, porém, em uma dúvida que se sustenta indefinidamente enquanto possibilidade, jamais se tornando realidade. A coquete implica-se em um jogo erótico de sedução, cujo fim não é a consumação do ato, mas a manutenção da proximidade, do estado de entremeios, no qual sua atitude de sedução e capacidade de desprezar prazer é a finalidade do comportamento. Nas palavras de Simmel, o que define propriamente a coquete

\begin{abstract}
é despertar o prazer e o desejo por meio de uma antítese/síntese original, através da alternância ou da concomitância de atenções ou ausência de atenções, sugerindo simbolicamente ao mesmo tempo o dizer-sim e o dizer-não, que atuam como que "à distância”, pela entrega ou a recusa - ou, para falar em termos platônicos, pelo ter e o não-ter -, que ela opõe uma à outra, ao mesmo tempo que as faz experimentar como a uma só vez. No comportamento coquete, o homem sente quão próximos e imbricados estão o ganhar e a impossibilidade de ganhar, que constituem a própria essência do "preço" e que, por essa inversão que faz do valor epígono do preço, fazem aparecer esse ganho como precioso e desejável. A essência do coquetismo, resumida num paradoxo, é a seguinte: onde há amor, há - em profundidade ou na superfície - ter e não-ter, portanto onde há ter e não-ter, se não numa forma real, ao menos sob a forma lúdica, há amor ou algo que é tido por ele. (SIMMEL, 1909: 95)
\end{abstract}

Assim, para Simmel (1909), a construção do comportamento coquete é a insinuação, o olhar interessado, a cabeça esquivada, cuja atenção em direção ao outro é posta em relevo para, em seguida, ser sugerida a retração. Nunca há um olhar direto e interessado, mas um meio-olhar, imbricado entre a distância e a reserva, o interesse e o desinteresse. Nesse comportamento dualista, qualquer decisão de fato, qualquer ato que ponha fim ao jogo, extingue a relação em si: o coquetismo pressupõe o jogo erótico e este é sua finalidade, nunca estando a ação plausível como real - "recusar e conceder é o que as mulheres sabem fazer com perfeição, e só elas sabem" (SIMMEL, 1909: 98).

No polo masculino, Simmel (1909) indica que o homem que se presta ao jogo erótico do coquetismo não o faz porque apenas "submisso", porém, principalmente, porque sente "um gozo e um prazer" (SIMMEL, 1909: 99) particulares 
nessa entrega nunca concretizada, visto que "uma série de acontecimentos vividos, orientada para um sentimento de felicidade final, já irradia sobre os momentos que o precedem uma parte do valor do prazer deste último" (SIMMEL, 1909: 99), de maneira que há uma antecipação da felicidade potencial final (realização da conquista e do ato) na simples possibilidade já gozada durante a efetivação do jogo, no momento do vivido: "a simples consciência de ter seu amor correspondido supera todas as alegrias eróticas por assim dizer mais substanciais" (SIMMEL, 1909: 100). Ainda do lado do comportamento masculino, o homem aprecia a dúvida por si só, pois o talvez lhe pareça mais aprazível que um sim ou um não, visto que não desejando um sim, não temerá um não (SIMMEL, 1909).

Simmel (2006) enquadra o coquetismo enquanto uma "forma lúdica de sociação" (interação) - ou sociabilidade - no qual o sentido final da relação é a dúvida e o jogo em si, nunca levado a termo. No coquetismo, "o conteúdo íntimo da sedução é transformado em cálculo espacial” (DOLZANI, 2013: 182), pois o desejo, enquanto manifestação fenomenal do amor, fundando-se no querer obter, passando a ser um desejo que se mantém pela dúvida da obtenção, valorado exatamente porque possível, mas talvez nunca alcançável.

$\mathrm{Na}$ construção da sua interpretação social do coquetismo, Simmel evoca, portanto, um comportamento da mulher cuja natureza flexiona-se na dúvida. O jogo de sedução levado a cabo pela mulher atrai e repudia. Assim, a análise simmeliana está centrada na relação em si, na ideia de sociabilidade, calcada na dúvida nunca resolvível, um ponto de definição do coquetismo que também define, psicanaliticamente, outro fenômeno, a histeria, montado na e pela clínica psicanalítica nascente.

Diante do quadro inicial exposto, não se trata, obviamente, de relacionar agora coquetismo e histeria no sentido ingênuo de supor que todas as mulheres coquetes seriam inequivocamente histéricas, ou de que o coquetismo é tão somente um sintoma histérico, pois, como ressaltado, os níveis de análise propostos pelos autores são diferentes entre si.

Contudo, a chave interpretativa e comparativa aqui é precisamente o inverso: supor que o coquetismo, como parte do comportamento da mulher frequente no final do século XIX e começo do XX pode, talvez, cristalizar o enredo de que as histéricas, no léxico freudiano, poderiam assumir o comportamento coquete como parte e expressividade, se permanecermos exclusivamente no mesmo léxico clínico freudiano, da sua estrutura psíquica, mantendo-se, portanto, coquetismo e histeria separados enquanto fenômenos e categorias analíticas, mas afins enquanto atos da esfera da existência e relacionáveis entre si.

Nesse sentido, é salutar o ensinamento do psicanalista M. Masud R. Khan (1997) de que o comportamento histérico se insinua sob a moralidade e contrições sexuais culturalmente inferidas de uma época, de maneira que a relação entre histeria e cultura não é algo desprezível na clínica analítica.

Descendo, paralelamente, ao nível clínico que inaugura a Psicanálise, Breuer (1996), em sintonia com Freud no começo dos Estudos sobre a Histeria, discorre sobre a "afetividade excessiva" que se apodera da atividade mental das histéricas, propondo que, normalmente, representações de cunho afetivo e excitativo são rechaçados da consciência:

As mais numerosas e importantes das representações que são rechaçadas e convertidas possuem um contexto sexual. [...] Certas moças defrontam-se com eles com total desembraço, havendo entre elas algumas que ignoram e fecham os olhos a todo o assunto. Outras aceitam-nos como os meninos, sendo esta dúvida a norma entre as moças das classes camponesa e trabalhadora. Outras, ainda, com uma curiosidade mais ou menos obstinada, correm atrás de qualquer coisa sexual que possam encontrar em conversas 
ou livros. E, finalmente, há naturezas de organização requintada que, embora seja grande sua excitabilidade sexual, possuem uma pureza moral igualmente grande e sentem que qualquer coisa sexual é algo incompatível com seus padrões éticos, algo de conspurcante e degradante. Elas recalcam a sexualidade afastando-a da consciência, e as representações afetivas de conteúdo sexual que provocaram os fenômenos somáticos são rechaçada e assim se tornam inconscientes. (BREUER, 1996: 263)

Nessa breve explanação, Breuer acentua o caráter de repressão de sexualidade que se afina com a aura da época, resvalando na tensão entre a excitabilidade sexual e outros padrões elevados de moral e ética que confluem para o recalque da sexualidade, ponto salientado por Khan (1997). Segue Breuer (1996) enfatizando que o recalcamento do sexual é intensificado nas moças suscetíveis a uma excitação sexual mesclada com medo e angústia, assustando-se com seus desejos.

Freud (1996), por sua vez, dialogando com as ideias expostas de Breuer, também identifica a etiologia das neuroses em fatores sexuais, em angústias e medos que se alocam no e contra o complexo da sexualidade a partir de processos psíquicos de recalque e resistência. Em "As neuropsicoses de defesa”, Freud (1894) é enfático ao afirmar que as representações recalcadas, levadas ao inconsciente, cujo quantum de excitação fica flutuante e desvinculado do recalcado, são principalmente as do campo da experiência e das sensações sexuais, representações desinvestidas, portanto, do caráter de efetivação plausível e possível:

[...] a descoberta mais importante a que chegamos, quando uma análise é sistematica-
mente conduzida, é a seguinte: qualquer que seja o caso e qualquer que seja o sintoma
que tomemos como ponto de partida, no fim chegamos infalivelmente ao campo da
experiência sexual. Aqui, portanto, pela primeira vez, parece que descobrimos uma
precondição etiológica dos sintomas histéricos. (FREUD, 1896: 196)

Ora, se histéricos, na famosa formulação de Freud, sofrem de reminiscências (FREUD, 1910[1909]), são as ideações recalcadas de conteúdo erótico e sexual que se impõem como fio condutor da análise da histeria. A satisfação autoerótica infantil fora substituída pelos ataques ou sintomas histéricos, centrados em fantasias cujos atos de realização são renunciados (FREUD, 1909 [1908]): entre a repressão e o retorno do que foi reprimido, fantasias condensam-se e organizam a "experiência histérica" sem, aparentemente, efetivação concreta do ato, permanecendo a fantasia como força pulsional do quantum afetivo e de excitabilidade que se depreendera daquele ato em si.

Nesse contexto, percebe-se que, na histeria, todo o corpo é erotizado dento de um panorama de inclinação para se defender da sexualidade. As histéricas, ideal-tipicamente, aparecem na teoria como exageradamente sensíveis, com propensão às divagações eróticas, àquelas fantasias cuja realização restou apenas em potência nunca realizada, visto que a anatomia da histeria é fantasística. Khan (1997) resume a sintomatologia histérica na metáfora de que a histeria é uma vivência passiva na expectativa entre uma plêiade de promessas possíveis e a recusa de satisfação das mesmas. Espelho dessas características sintomáticas é o fato de que as histéricas, por centrarem no corpo as afecções desejantes e pulsionais, demarcam sua personalidade com excessos e inclinações dramáticas, performáticas, eternas demandantes de ações do outro, embora "a vida interior do histérico se torna um cemitério de recusa" (KHAN, 1997: 57). Assim, se o corpo fala, o da histérica, hipersensível inclusive nos sentimentos, grita. 
Na esteira de Freud, Simmel e da proposta comparativa, a histeria, enquanto condição e estrutura psíquica, parece encontrar no coquetismo, como realidade social, um terreno fértil de expressividade. Entram em jogo no coquetismo as ideias de sedução, erotismo não realizado e performance, os quais são elementos capitais da condição histérica. Ademais, considerando-se a temporalidade dos escritos, tal qual Simmel (1909) demonstrou, é pelo comportamento do/no corpo da mulher, espacialmente situando-se entre o sim e o não da realização erótica, que o coquetismo acontece, afim, portanto, da histeria proposta por Freud.

Joel Dör (1991) enfatiza que o traço estrutural da histeria é a problemática em relação ao desejo. Baseado em Freud, o desejo da histérica é a permanência da insatisfação do desejo. Nega-se o ter pela assunção do desejo insatisfeito, e, na relação com o sexual, o ideal de perfeição irrealizável dirige a indecisão permanente da histérica (mesmo quando há decisão) com qualquer coisa, o que se torna, no jogo do coquetismo, uma vantagem para uma coquete-histérica hipotética, com o desejo ideal de um objeto ideal permanecendo sempre irrealizado em prol da insatisfação, à qual tão apaixonadamente ela se dedica:

\begin{abstract}
Quer se trate das coisas mais ordinárias da vida cotidiana, ou de negócios menos banais que engajam a ordem das coisas a um termo mais longo, a estratégia sintomática permanece idêntica, concernindo, por exemplo, à escolha de uma roupa, de um par de sapatos, de uma marca de pasta de dentes, ou, até mesmo, de um parceiro amoroso. Quando, assim mesmo, a escolha acaba por se fazer, tanto por desgaste como por cansaço, o objeto eleito continua sua carreira de incerteza, dúvidas e arrependimentos. As negociações intermináveis que daí resultam apenas redobram a hesitação inicial: nenhum objeto escolhido será suscetível de garantir ou de preencher sua função de maneira melhor apropriada do que aquele que foi precisamente relegado. (DÖR, 1991: 77)
\end{abstract}

Assim, parece que o coquetismo encontra a histeria já que não se trata, para a mulher coquete, de um jogo com vista a um fim. Trata-se de um jogo que se mantém enquanto e apenas como jogo. Sendo um fim em si, o coquetismo jaz como possibilidade literal da expressão de uma fantasia jamais realizada, retirando da possibilidade do "talvez" a satisfação do gozo sempre porvir, nunca efetivo. Indo além e retomando Dör (1991), se a insatisfação é condição par excellence da histeria, ela o é pela convicção permanente da imperfeição (DÖR, 1991: 77), e, no coquetismo, há a percepção de que, imperfeitos se comparados ao ideal de perfeição que levaria à realização do ato, os possíveis amantes "jogados" pela coquete-histérica habitarão sempre o reino da probabilidade, ruminando um gozo fantasioso pela performance do "sempre te quero, nunca te terei".

Voltando a Simmel,

\begin{abstract}
A coquete exagera ao máximo seus atrativos, à medida que atrai o homem para bem perto de si, como se não levasse a situação verdadeiramente a sério. Seu comportamento oscila entre o sim e o não, sem marcar uma posição definitiva. Ela desenha assim a forma simples e pura das decisões eróticas, e pode sintetizar, em um comportamento coeso, suas oposições polares, uma vez que o conteúdo decisivo e definitivo que a situaria em um dos dois polos não faz parte, por princípio, do coquetismo. Esse desafogar-se do peso de todo conteúdo fixo e das realidades permanentes dá à coqueteria aquele caráter de oscilação, de distância, de ideal, em função do qual se fala com uma certa razão de "arte" - e não somente de "artifícios" - do coquetismo. (SIMMEL, 2006: 73)
\end{abstract}

Sendo o coquetismo um jogo de sedução, portanto, a insatisfação do desejo é a mola propulsora que estabelece a afinidade com a histeria. Não se trata de uma dúvida permanente, como no caso da neurose obsessiva, onde não se quer escolher, ou não se consegue escolher. No coquetismo, há, por outro lado, de fato, uma escolha, e ela é $o$ jogar, o permanecer no jogo erótico, o inclinar-se entre o 
sim e o não sem permitir a efetivação do ato. Escolhe-se, ao se aproximar o coquetismo da atividade histérica, o jogo e apenas o jogo, resvalando uma possível insatisfação devido ao fato de que tal escolha nunca foi a realmente desejada, pois a concretização da sedução com a condensação do ato não acontece. Fantasia-se o gozo jamais o realizando, e a histérica-coquete, estruturada sobre a expansividade e a performance, encontra outro pilar para sua condição no coquetismo: joga-se com o outro, joga-se $o$ outro, enlaça-se o candidato a amante numa rede de sedução onde o próprio objeto do desejo também é a plateia ideal, já que, nunca escolhido, ele observa a histérica-coquete atendendo a suas demandas e permanecendo no jogo de irrealização, menos jogando e mais sendo jogado, observando-a sem ir embora.

Convergem, assim, o coquetismo e a histeria exatamente na dinâmica que Dör (1991) explica sobre a hesitação histérica: a histérica não fixa sua escolha no primeiro homem que se apresente, mas permite que a escolha seja sempre passível de revisão. Se e quando houver um escolhido, ele será de segundo porte, jamais próximo do real-desejado imposto pela perfeição. Nesse sentido, atirar-se ao coquetismo, ao jogo, é, por outro lado, enfatizar a dinâmica histérica da hesitação: sem escolha, sempre há revisão; sem perfeição, sempre há possibilidade; sem efetivação, sempre haverá desejo insatisfeito e, nele, gozo.

Por fim, coquetismo e histeria, condições sociais de estruturação de jogos eróticos e estrutura psíquica, encontram uma afinidade na comparação teórica aqui proposta. No campo do talvez, no gozo antecipado enfraquecido, na insatisfação dos desejos, no implicar-se em uma sociabilidade que parece poder dar vazão à condição histérica, a coquete-histérica assume a condição dúbia que encerra sua natureza: sei o que quero, mas prefiro não realizar; talvez saiba o que desejo, atuo para conseguir, todavia melhor permanecer na segurança hesitante do nãoquase-sim, encapada sob a capa da possibilidade; se meu corpo deseja, melhor desejar à distância segura, nas fantasias que tanto amo. Entre o coquetismo e a histeria, realiza-se (quase) nada e, assim, goza-se na e pela irrealização, irrealização montada por entre as teias da moralidade da época e das contrições sexuais que controlam corpos culturalmente.

Se, como afirma J.-D. Nasio (1991), a histeria é um "estado fantasístico de insatisfação" (NASIO, 1991: 15-6), no campo do jogo coquete do comecinho do século XX, a realização insatisfeita é o fim valorado em si da sociabilidade do jogo erótico traduzido por Simmel (1909) dentro das conformidades culturais de regulação dos corpos da época. Nos dois níveis distintos, consequentemente, parece ser a insatisfação e o jogo o tom do núcleo das propostas teóricas.

Bem, os envolvidos, insatisfeitos, agradecem.

Recebido em 3 de julho de 2019

Aceito em 12 de novembro de 2020 


\section{Referências}

BREUER, J. “Considerações Teórica”. In: FREUD, S. Estudos sobre a Histeria (1893-1895). Obras completas de Sigmund Freud: edição standard brasileira. Vol. II. Rio de Janeiro: Imago, 1996. pp. 207 - 271.

COSSI, Rafaela Kalaf. "Luce Irigaray e a Psicanálise: uma crítica feminista”. Gerais: Revista Interinstitucional de Psicologia, 12 (2): 319-337, 2019.

DOLZANI, Miriam. As formas eróticas em Simmel. Intratextos, 4 (1): 180-193, 2013.

DÖR, Joel. Estruturas e clínica psicanalítica. Rio de Janeiro: Livrarias TaurusTimbre Editores, 1991.

FREUD, S. Estudos sobre a Histeria (1893-1895). Obras Completas de Sigmund Freud: Edição Standard Brasileira. Vol. II. Rio de Janeiro: Imago, 1996.

FREUD, S. "As neuropsicoses de defesa" (1894). In: FREUD, S. Primeiras Publicações Psicanalíticas (1893-1899). Obras Completas de Sigmund Freud: Edição Standard Brasileira. Vol. III. Rio de Janeiro: Imago, 1996. pp. 51 - 74.

FREUD, S. “A etiologia da histeria (1896)”. In: FREUD, S. Primeiras Publicações Psicanalíticas (1893-1899). Obras Completas de Sigmund Freud: Edição Standard Brasileira. Vol. III. Rio de Janeiro: Imago, 1996. pp. 187-218.

FREUD, S. "Algumas observações gerais sobre os ataques histéricos (1909 [1908])". In: FREUD, S. Gradiva de Jensen e outros trabalhos (1906-19o8). Obras Completas de Sigmund Freud: Edição Standard Brasileira. Vol. IX. Rio de Janeiro: Imago, 1996. pp. 207 - 216.

FREUD, S. "Cinco lições de psicanálise (1910[1909])". In: FREUD, S. Cinco Lições de Psicanálise, Leonardo da Vinci e outros trabalhos. Obras Completas de Sigmund Freud: Edição Standard Brasileira. Vol. XI. Rio de Janeiro: Imago, 1996. pp. 25-66.

KHAN, M. Masud R. "O rancor da histérica”. In: BERLINCK, Manoel Tosta (org.). Histeria. São Paulo: Editora Escuta, 1997, pp. 49-60.

MELO SILVA, Lígia Mychelle de. A arte do coquetismo na poesia de Florbela Espanca: uma leitura do erótico no soneto "Realidade". Revista dEsEnrEdoS, 11 (III): 1-6, 2011.

NASIO, J.-D. A Histeria: teoria e clínica psicanalítica. Rio de Janeiro: Zahar, 1991.

SIMMEL, G. "Psicologia do Coquetismo" (1909). In: SIMMEL, Georg. Filosofia do Amor. São Paulo: Martins Fontes, 2006.

SIMMEL, G. Questões fundamentais da sociologia. Rio de Janeiro: Jorge Zahar Ed., 2006. 